\section{Making the Choice between Rewholesalers and Other Nursery Market Channels}

\author{
Marco A. Velástegui Andrade ${ }^{1}$ and Roger A. Hinson ${ }^{2,3}$ \\ Department of Agricultural Economics and Agribusiness, LSU AgCenter, \\ 101 Ag. Administration Building, Baton Rouge, LA 70803
}

Additional index words. market channels, mass merchandisers, garden centers, landscapers, rewholesalers, multinomial logit

\begin{abstract}
Alternative market channels that include garden centers, landscapers, mass merchandisers, and rewholesalers have contributed to the growth of ornamental crops sales in the United States. Knowledge about growers' use of these channels is indispensable for the development of appropriate strategies to achieve goals. This study estimated the impacts of growers' business characteristics on market channel choice by firm size. The explanatory variables were evaluated separately but were grouped by regions of the United States, kind of plant, kind of contract sales, and promotion behavior. Growers' location had limited effect on channel choice when compared with growers in the south. Growers with a more diversified marketing strategy were associated with higher likelihood of using the mass merchandiser and garden center channels. Trade show attendance had a strong negative impact on choice to the mass merchandiser compared with the rewholesaler channel. Generally, there appeared to be differences in the groups of variables that were related to channel choice. By channel, plant groups were important in explaining the mass merchandiser and landscaper channels, and the contracts group affected the garden center choice. By size, the contracts variables impacted the mass merchandiser channel, plant groups variables impacted the garden center channel, and promotions variables impacted the landscaper channel.
\end{abstract}

In the United States, the total value of sales of greenhouse and nursery crops increased $\approx 18 \%$ between 2000 and 2006 according to the ERS/USDA (2007). This growth may have been encouraged by the availability of sales opportunities within the set of market channels that already existed at that time. In a 2003 survey, sales were collected for five marketing channels: mass merchandiser retailers, home centers, garden centers, landscapers, and rewholesalers (including horticultural distribution centers). By leading channels, $25.9 \%$ of growers' sales were to the rewholesaler channel behind only the landscaper channel at $33.9 \%$. In some states, rewholesaler was the channel most used for sales of ornamental plants. From 1998 to 2003 , sales to rewholesalers jumped from $20.6 \%$ to $40.1 \%$ in Louisiana and from $17.9 \%$ to $42.2 \%$ in California. The rewholesaler channel is an important selling option (Brooker et al., 2005).

A variety of incentives and disincentives affect growers' preferences for and use of channels. Hampton's (2001) work suggested that growers preferred garden center customers who are less price-sensitive because their competitive position in the retail market often is based on quality and service. Similarly,

Received for publication 3 Oct. 2008. Accepted for publication 4 Jan. 2009.

${ }^{1}$ Graduate Assistant

${ }^{2}$ Professor.

${ }^{3}$ To whom reprint requests should be addressed; e-mail rhinson@agcenter.1su.edu. landscapers may be less sensitive to price because they provide value-adding services to plant material. On the other hand, mass merchandisers, with a high volume/low price retail strategy, usually have business relationships in which price is a key factor. In addition, minimum quantity requirements, price concessions, and other services may be required to make the sale. The rewholesaler business model differs substantially from the other channels. Positioned as middlemen in the supply chain and therefore susceptible to price, rewholesalers provide services, including product accumulation, broad product lines, and placement of materials, at locations convenient to the trade, particularly for the landscaper customer. The rewholesaler activity also may be part of a production nursery, or the distribution center may have a retail garden center component.

Given these considerations, a common expectation is that growers prefer to sell to landscapers and garden center retailers to capture better margins, but usually use a combination of channels for reasons that include risk management. Knowledge about characteristics of marketing channels is indispensable for the development of risk and sales strategies that enhance profitability and market functionality and improve service quality and price to the consumer.

Alternative research suggests that growers' decisions about production (plants and quantities) are influenced by channel characteristics and other descriptors of the firm such as age, size, and combination of plant materials produced. For example, Hampton (2001) indi- cated that although large and small growers have similar products, their shares of production differ. Large growers typically produce more annual bedding plants (the leading plant category for mass merchandisers), evergreen trees, and broad-leaved evergreen shrubs. Because large nurseries typically are suppliers to large retailers, and because the annual bedding plants category is a higher proportion of sales for large nurseries, the channel choice will be affected by grower size as measured by sales.

Hinson and Turner (1994) hypothesized that marketing channel choice was influenced by grower characteristics, including age, size, propensity to negotiate, channel diversification, organizational structure, competitive pressures, and location of the nursery. In their study, higher price negotiation was associated with a lower (higher) proportion of sales to landscapers (rewholesalers). In addition, a similar association with these channels was observed when the growers were located in the west region. Age of the firm did not have a significant effect on sales to these channels.

Hampton (2001) analyzed channel choice and differences between small and large firms with $\$ 200,000$ as the sales boundary. In that study, smaller growers were expected to concentrate ornamental sales on traditional garden center and landscaper channels. Their selling and marketing activities included local and regional trade shows, walk-in customers at the nursery site, and telephone sales. Meanwhile, larger nurseries attended more and larger trade shows and used more active sales tactics such as an outside sales force. Furthermore, they appeared to prefer to serve the mass merchandiser and rewholesaler channels, presumably because these offer growth opportunities. These expectations were confirmed, because there were no significant variables for the mass merchandiser channel in the small grower model and few for the rewholesaler channel.

Therefore, a better understanding of these market channel conditions should contribute to better management strategies. In this article, the objective is to explain the relationship between the commercial grower's most used marketing channel choice and a set of business characteristics and attitudinal variables of these individuals as identified in the literature.

\section{Materials and Methods}

Data about trade flows, marketing practices, and firm characteristics were collected in a survey covering the 2003 calendar year. The survey effort targeted all states, but only 44 participated. From lists of licensed nursery growers obtained from state trade associations and regulatory agencies, a sample of 15,588 growers was chosen (Brooker et al., 2005). Dillman's (2000) protocol was used to design and implement the mail survey. There were 2485 respondents for a $15.9 \%$ response rate. Observations were screened and were dropped from the data set if the following conditions held: 
1. Information about sales was incomplete or inconsistent;

2. The percent of wholesale sales through the marketing channels did not sum to $100 \%$. If otherwise acceptable, those observations in which market channels summed to at least $90 \%$ were increased proportionally;

3. They were outlier observations with respect to age;

4. Advertising expenditure was not reported;

5. Gross sales were $\$ 10,000$ or less, to be consistent with the USDA definition of commercial production; and

6. Seventy percent or more of sales was to retail customers.

Imposition of these conditions reduced the number of observations to 1200 .

The mass merchandiser and home center categories were merged. The channels were observed to be similar in terms of sales levels, had similar percentages of sales and categories of plant materials by channel, and were expected to be similar in quality standards, price policy, and line of products.

The impact of business characteristics on market channel use was analyzed by firm size (large or small) as measured by sales. The sales boundary chosen to distinguish the two size groups was guided by expected differences in management behavior between sizes and by the survey's format for reporting sales. Respondents could choose from 11 predefined sales ranges or could write in their actual sales value. The choice of boundary between large and small was constrained by these ranges. Sample size needs in each group also were important. The boundary chosen was $\$ 500,000$, generating 510 observations at or above this level and 690 observations below.

As stated, the objective was to investigate the grower's preferred marketing channel with an emphasis on the rewholesaler channel given its increasing importance. The data set did not explicitly identify which of the alternatives was most preferred, so it was assumed that the channel with the largest percentage of sales was the grower's favored choice. Some growers indicated equal percentages of sales in two or more channels. These "ties" were broken by assuming that the most used channel, as measured by highest average percentage, was the choice. Because channel is a discrete choice, the multinomial logit model, in which the decision-maker (grower) chooses between mutually exclusive and unranked alternatives (the four marketing channels), is appropriate (Pindyck and Rubinfield, 1998). This model was estimated using the -mlogit- command of the STATA software package (StataCorp LP, 2005), a maximum-likelihood procedure, which algebraically is shown as:

$\log \left(\frac{P_{j i}}{P_{4 i}}\right)=\beta_{j 4}+\beta_{j 4} X_{i}+\beta_{j 4} Y_{i}+\beta_{j 4} Z_{i}+\ldots . .+\mu_{i}$

where: $\beta=$ unknown parameters; $i=$ individual firm; $\mathrm{j}=(1)$ mass merchandiser, $\mathrm{j}=(2)$ garden center, $\mathrm{j}=(3)$ landscape growers; $\mathrm{P}_{\mathrm{ji}}=$ probability that individual $i$ will chose category $\mathrm{j} ; \mathrm{P}_{4 \mathrm{i}}=$ probability that individual chose the baseline category (rewholesalers); X, Y, $\mathrm{Z}=$ explanatory variables; and $\mu_{\mathrm{i}}=$ residual assumed to be independently and normally distributed.

Variables and their expected influence. The independent variables included in the final econometric model are described in Table 1. Estimated coefficients in the multinomial logit model have a distinct interpretation. The estimate is the logarithm of the relative probability that a producer would choose a specified channel compared with the base (rewholesaler) channel. A positive sign for estimated coefficients is interpreted as a higher likelihood of choosing the alternative channel over the base. The opposite conclusion is appropriate for coefficients with a negative sign. The expected signs, discussed subsequently, are based on characteristics of wholesale outlets as presented in the review of literature.

The variables plant groups, negotiated sales, contract sales, and advertising and promotional expenditures were reported in the survey as percents of sales (Table 1). After sales value was determined (actual value of sales was used if reported, and if not, the midpoints of the 11 predefined categories were used), dollar values for each of these variables was calculated as the product of total sales and percent. These "sales-weighted" variables gave more emphasis to larger nurseries and were converted from a $\$ 1$ to a $\$ 100,000$ unit basis for easier presentation.

Most variables could be placed in one of four groups: regions, plant groups, measures of contract sales, and kinds of promotions.
Regional differences were expected, but there is little research to indicate specific regional relationships between the rewholesaler base and the other channels. Generally, increases in industry production have occurred in the south and west, and mass merchandisers' share of retail sales has increased. When compared with the south region (the base), concentrations of larger nurseries in the west were expected to indicate a higher likelihood for the mass merchandiser. The lower price sensitivity of garden center and landscaper channels might positively affect the attractiveness of these channels over rewholesalers in some regions.

Sales by plant groups were reported as percent of total sales in 16 prechosen kinds of plants and were converted to dollars of sales (Brooker et al., 2005). Included separately, the parameter estimates were seldom significant. Under the guidance of a university horticulturist, the original categories were combined into five groups with similar production characteristics: trees/shrubs included deciduous shade and flowering trees and shrubs, broad-leaved and narrow-leaved evergreen shrubs, fruit trees, and evergreen trees and was $44.9 \%$ of sales; bedding plants included bedding plants, flowering annuals and vegetables, fruits and herbs, and flowering potted plants and was $20.2 \%$; vines included vines and groundcovers, roses, and herbaceous perennials and was $14.2 \%$; foliage was $3.9 \%$ of the total; and all other was $16.8 \%$

Information about shares of plant group sales by market channel is limited. However, the vines and bedding plants groups were expected to be positive for all the marketing channels compared with the rewholesaler,

Table 1. Description of variables in the econometric model.

\begin{tabular}{lc}
\hline Variable & Description \\
\hline Regions & Dummy_standard US Census regional definitions \\
Northeast, west, midwest, & for northeast, west, midwest, and south \\
$\quad$ and south (0 if false, 1 if true) & Proportion of total sales in each of five plant categories \\
Plant groups & ("other" was not included in model) \\
Plant groups: trees/shrubs, & \\
bedding plants, vines, and foliage & Dollar value of total sales contracted or sold \\
Measures of contract sales & before produced \\
Total sales under contract & \\
& Dummy - had contract sales to each kind of customer \\
Contracts with other producers, &
\end{tabular}

garden centers, or mass merchandisers ${ }^{y}$ ( 0 if false, 1 if true)

Kinds of promotions

Trade shows attended $\quad$ Number of trade shows attended in 2003

Web site promotion ${ }^{2}$

Trade show promotion ${ }^{2}$

Other variables

Firm age

Computer management aids ( 0 if false, 1 if true)

Channel diversity ( 0 if false, 1 if true)

Uniqueness as pricing factor (0 if minor importance, 1 if somewhat or very important)

Proportion of negotiated sales ${ }^{\mathrm{z}}$

${ }^{\mathrm{z}}$ Sales-weighted variables.

"The "contract" described here almost always is informal.
Dollar value of web site promotion expenses

Dollar value of trade show promotion expenses

2004 minus year established

Dummy - the firm used or planned to use at least four computer functions to aid management from a list of 11

Dummy - the respondent had sales in at least three of five marketing channels

Dummy - rating of importance of product uniqueness to price determination

Sales in which conditions such as price were negotiated 
because they are decorative, colorful, and visually appealing plants. Trees/shrubs and foliage were expected to be a positive for garden centers because they provide variety and unique products, including large-sized tree, shrubs, and foliage. However, for the landscaper channel, foliage was expected to be negative because landscapers may have few applications for these plants. The "other plants" group was not included in the model as a result of its diverse content.

Measures of contract sales, defined as materials sold before being planted, was measured in several ways. Total sales under contract, a continuous variable, measured the dollar value of all the grower's contracts. Because mass merchandisers are very aggressive in assuring their stores are supplied, this channel was expected to have a positive sign. The signs for garden center and landscaper channels would be less clear. Other measures of contract activity were dummy variables measuring whether a contract relationship existed with buyers in other channels. Contracts with other producers, with garden centers, and with mass merchandisers should have positive signs for the specific channel, because growers plan their production activities to satisfy the contract. Given that relationship, we expected a negative impact on sales compared with the rewholesaler channel when growers had contracts with any of the other channels.

Promotion expenditures (trade shows attended and expenditures on web sites and trade shows promotion) were expected to affect the likelihood of choosing other channels compared with the rewholesaler channel. Note that mass merchandisers typically source plant material through buyers, so an expected sign there would have little relevance. Attending trade shows is costly and large nurseries might have a positive sign for all the channel comparisons because they were more likely to attend. Garden center and landscaper channels often do locate sources at trade shows, so positive signs were expected.

Negotiated sales activity may be more frequent between nurseries and mass merchandisers because of product volume and price pressures, implying a positive sign on the coefficient. Sales terms also are negotiated in the grower-to-garden center and landscaper relationships. Although these channels are more quality-oriented, the relationship was uncertain because negotiation was defined as discussion of price and other factors, including quality.

Some variables did not fit into the groups discussed. Channel diversification is a risk management tactic. When three or more channels were used, the mass merchandiser channel was expected to be positive. Older firms were expected to have a more diversified marketing strategy that implies use of a rewholesaler channel, so a negative sign was expected. This relationship, however, was expected to be positive for the mass merchandiser channel given that more established firms tend to be larger, possibly with a stronger market position, and offering a better opportunity to increase volume. In addition, nurseries using the mass merchandiser channel are expected to need more computer assistance for management functions (measured by whether they used at least three of these) to fulfill the conditions of sale and inventory replenishment systems required, implying a positive sign.

Other variables were included in preliminary model runs based on literature review and on theoretical considerations. Variables excluded from the final model because of lack of significance were:

1. Individual computer based management aids such as bar coding and landscape design software;

2. Contracted production with cooperatives;

3. Number of temporary and permanent employees;

4. Advertising expenditure on yellow pages, billboards, newsletter. and other promotion alternatives;

5. Sales - correlation with other variables resulted in statistical issues resulting in failure of the model to converge; and

6. Interactions variables: sales-age, sizegroups of plants, trade shows-plant groups.

\section{Results and Discussion}

In this section, results from the estimation of the multinomial logit model are presented. Discussion of the results focuses on the three comparisons within the model: the comparisons of mass merchandiser, garden center, and landscaper channels to the rewholesaler channel. Because the study embraces the hypothesis that channel choice is influenced by firm size, separate models were estimated for large and small firms to understand the differing impacts of size on the channel choice. In a next section, the three comparisons within the model are evaluated in terms of individual variables that were found to be significant.

In terms of goodness of fit, the model had acceptable measures. The likelihood ratio $\chi^{2}$ was -683.38 and -487.61 for small and large growers, respectively, and the pseudo- $R^{2}$ measures were 0.20 and 0.27 . These measures were statistically significant.

As indicated in the literature review and in the discussion of expected direction of influence of the explanatory variables, there is relatively little precedent to guide those expectations. Therefore, findings from model results are exploratory in nature and are expected to be evaluated and refined through additional research. For that reason, the 0.10 level was chosen to indentify significant coefficient estimates. This decision rejects fewer variables and provides the basis for a broader understanding of how producers' business characteristics are related to channel choice.

Estimated coefficients in the multinomial logit model (MNL) are changes in probability of use of a channel relative to the base, when levels of the independent variables changes. In this study, the estimates are the log of the ratio of the probability of choosing one marketing channel [mass merchandiser (MM), landscaper (LD), or garden center (GC)] over the probability of choosing the rewholesaler (RW). Results for each comparison are presented in columns in Table 2. A positive coefficient estimate means that an increase in an explanatory variable increases the $\log$ odds ratio and is interpreted as an increase in the likelihood of use of that channel compared with the rewholesaler, and conversely, a negative coefficient reveals a lower likelihood of use of that channel. A negative coefficient also can be interpreted as an increased likelihood of use of a rewholesaler.

Implications for channel differences by marketing channel. Discussion of the results is organized around the channel comparisons and the firm size distinction. As an example of interpretation of MNL results, we use the trees/shrubs coefficient for small growers in the mass merchandiser column (Table 2). This is a continuous variable with a dollar value corresponding to the total sales of deciduous shade and flowering trees and shrubs, broad-leaved and narrow-leaved evergreen shrubs, fruit trees, and evergreen trees. The example highlights the relative change of the MM channel to RW. The negative and significant coefficient for trees/shrubs means that when growers' sales of plants within this plant group increased, use of mass merchandisers was less likely than rewholesalers. In the following discussion, we use the terminology lower MM to RW likelihood (LD or $\mathrm{GC}$ as appropriate) to describe the negative result and higher MM to RW likelihood for the positive result.

Mass merchandiser channel comparison. From Table 2, there were no significant regional differences between the south and the other regions. Among the plant groups, increased sales of trees/shrubs by small growers decreased the MM to RW likelihood, but there was no impact for large growers. In contrast, an increase in sales of the bedding plants and the vines groups increased the MM to RW likelihood for both grower sizes.

For the variables that measured aspects of contract sales, differences between small and large firms were evident. As expected, for both firm sizes, contracts with mass merchandisers had a higher MM to RW likelihood. However, higher total sales under contract and contracts with other producers or garden centers were significant for small growers only and decreased the MM to RW likelihood. For contract sales, this was expected because small growers may find that conditions of sale imposed by mass merchandisers are difficult to meet. Contracts with garden centers increased the MM to RW likelihood for small growers only.

Promotional activities also had significant impacts. For both sizes, attending more trade shows decreased the MM to RW likelihood and more expenditure on trade shows promotion 
Table 2. Results from multinomial logit models, by size and marketing channel.

\begin{tabular}{|c|c|c|c|c|c|c|}
\hline \multirow[b]{2}{*}{ Variables } & \multicolumn{2}{|c|}{ Mass merchandiser/rewholesaler } & \multicolumn{2}{|c|}{ Garden center/rewholesaler } & \multicolumn{2}{|c|}{ Landscaper/rewholesaler } \\
\hline & Large & Small & Large & Small & Large & Small \\
\hline \multicolumn{7}{|l|}{ Regions } \\
\hline Northeast & $-1.103(0.672)$ & $0.133(0.580)$ & $0.345(0.408)$ & $0.425(0.341)$ & $-0.391(0.370)$ & $-0.001(0.304)$ \\
\hline Midwest & $-0.895(0.821)$ & $0.222(0.857)$ & $-0.999(0.626)$ & $0.651^{\mathrm{z}}(0.368)$ & $0.525(0.393)$ & $0.270(0.302)$ \\
\hline West & $-0.668(0.518)$ & $0.738(0.478)$ & $-0.049(0.389)$ & $-0.394(0.350)$ & $-1.338^{\mathrm{y}}(0.358)$ & $-0.887^{\mathrm{y}}(0.298)$ \\
\hline \multicolumn{7}{|l|}{ Plant groups } \\
\hline Trees/shrubs & $0.010(0.009)$ & $-1.355^{\mathrm{y}}(0.485)$ & $0.004(0.008)$ & $0.041(0.140)$ & $0.018^{\mathrm{y}}(0.007)$ & $0.398^{\mathrm{y}}(0.111)$ \\
\hline Bedding plants & $0.022^{\mathrm{y}}(0.009)$ & $0.905^{\mathrm{y}}(0.330)$ & $0.016(0.013)$ & $0.743^{y}(0.258)$ & $0.005(0.013)$ & $0.022(0.267)$ \\
\hline Vines & $0.062^{\mathrm{y}}(0.028)$ & $2.064^{y}(0.568)$ & $0.101^{\mathrm{y}}(0.026)$ & $1.713^{\mathrm{y}}(0.543)$ & $0.074^{\mathrm{y}}(0.025)$ & $1.6397^{\mathrm{y}}(0.528)$ \\
\hline Foliage & $0.015(0.023)$ & $-0.039(0.333)$ & $-0.135^{\mathrm{y}}(0.064)$ & $-0.242(0.272)$ & $-0.107^{\mathrm{y}}(0.042)$ & $-0.464^{z}(0.265)$ \\
\hline \multicolumn{7}{|l|}{ Measures of contract sales } \\
\hline Total sales under contract & $0.001(0.013)$ & $-1.215^{\mathrm{y}}(0.479)$ & $-0.141^{\mathrm{y}}(0.044)$ & $-0.739^{y}(0.323)$ & $-0.032^{\mathrm{y}}(0.015)$ & $-0.234(0.226)$ \\
\hline Contract to other producers & $-0.745(0.465)$ & $-1.752^{y}(0.574)$ & $-1.608^{\mathrm{y}}(0.425)$ & $-2.454^{y}(0.392)$ & $-1.157^{\mathrm{y}}(0.315)$ & $-1.534^{\mathrm{y}}(0.270)$ \\
\hline Contract to garden centers & $-0.581(0.605)$ & $1.709^{y}(0.525)$ & $2.237^{\mathrm{y}}(0.477)$ & $2.196^{\mathrm{y}}(0.353)$ & $0.476(0.433)$ & $0.739^{\mathrm{y}}(0.333)$ \\
\hline Contract to mass merchandisers & $2.733^{y}(0.517)$ & $1.979^{y}(0.655)$ & $-0.672(0.640)$ & $-0.065(0.668)$ & $-1.408^{\mathrm{y}}(0.640)$ & $-0.999(0.728)$ \\
\hline \multicolumn{7}{|l|}{ Kinds of promotions } \\
\hline Trade shows attended & $-0.181^{\mathrm{y}}(0.069)$ & $-0.377^{z}(0.223)$ & $0.004(0.052)$ & $-0.073(0.100)$ & $-0.029(0.044)$ & $-0.1613^{\mathrm{z}}(0.088)$ \\
\hline Web site promotion $(\$)$ & $0.522(1.423)$ & $0.283(9.976)$ & $0.860(1.687)$ & $8.099(6.029)$ & $1.395(1.420)$ & $4.318(6.029)$ \\
\hline Trade show promotion $(\$)$ & $-0.079(0.074)$ & $15.352^{y}(6.966)$ & $-0.886^{\mathrm{z}}(0.528)$ & $0.794(4.929)$ & $-1.075^{\mathrm{y}}(0.433)$ & $-0.290(3.894)$ \\
\hline \multicolumn{7}{|l|}{ Others } \\
\hline Firm age & $-0.003(0.010)$ & $-0.014(0.012)$ & $-0.007(0.006)$ & $0.000(0.007)$ & $-0.016^{\mathrm{y}}(0.006)$ & $0.001(0.006)$ \\
\hline Computer management aids & $0.603(0.648)$ & $0.096(0.419)$ & $0.099(0.420)$ & $-0.050(0.256)$ & $0.050(0.341)$ & $0.288(0.212)$ \\
\hline Channel diversity & $1.641^{\mathrm{y}}(0.540)$ & $1.415^{\mathrm{y}}(0.432)$ & $0.713^{\mathrm{y}}(0.341)$ & $0.378(0.283)$ & $0.056(0.263)$ & $-0.163(0.247)$ \\
\hline Uniqueness as pricing factor & $0.041(0.418)$ & $-1.014^{y}(0.418)$ & $-0.025(0.315)$ & $-0.727^{y}(0.263)$ & $0.172(0.261)$ & $-0.604^{y}(0.223)$ \\
\hline Proportion of negotiated sales & $0.010(0.007)$ & $0.189(0.342)$ & $-0.005(0.010)$ & $-0.347(0.219)$ & $-0.001(0.006)$ & $-0.289^{\mathrm{z}}(0.154)$ \\
\hline Constant & $-2.841^{\mathrm{y}}(0.848)$ & $-1.452^{\mathrm{y}}(0.596)$ & $-0.518(0.525)$ & $-0.037(0.350)$ & $1.116^{\mathrm{y}}(0.415)$ & $0.759^{\mathrm{y}}(0.289)$ \\
\hline
\end{tabular}

Rewholesaler is the reference group.

zignificant at the 0.10 level.

ySignificant at the 0.05 level; SES in parentheses; unit for the sales-weighted estimated coefficients is a $\$ 100,000$ change in the independent variable.

Source: Multistate Regional Project S-1021 survey, 2004.

by small growers increased the MM to RW likelihood. Among other variables, channel diversity (increased MM to RW likelihood) was significant for both sizes and the sign was as expected.

Garden center channel comparison. We observed only one significant difference in the regional analysis, and in that case, location in the midwest increased the GC to RW likelihood for small growers (Table 2).

For the plant groups, there appeared to be important size impacts. An increase in sales of bedding plants increased the GC to RW likelihood for small growers, whereas an increase in foliage decreased the measure for large growers. For both grower sizes, additional sales of vines increased the GC to RW likelihood. Because these are important products for garden centers, the likelihoods increased for all groups except foliage.

The contracts variables had a significant impact on the GC to RW likelihoods for large and small growers, except for contracts with mass merchandisers. As would be expected, growers who reported contract relationships with garden centers had increased GC to RW likelihood. An increase in total sales under contract and reporting contracts with other producers significantly reduced the GC to RW likelihoods. These results may suggest that the additional product moving into the supply chain for garden centers affects product availability for other channels. These contracts outcomes did not suggest differences in behavior between large and small growers.

Most other variables included in the model had no significant impact on the GC to RW likelihoods. Exceptions for large growers included trade shows promotion spending, which decreased the GC to RW likelihood, and the channel diversity variable that increased that likelihood.

Landscaper channel comparison. We found more regional impacts when investigating the landscaper relationship. When growers in the west were compared with growers located in the south, the coefficients were significant and negative for large and small nurseries (Table 2), indicating a lower LD to RW likelihood. Stated another way, western growers (compared with those in the south) were more likely to sell to rewholesalers than to landscapers.

The plant groups variables were important impacts on this relationship. Significant coefficients for trees/shrubs and vines for both grower sizes increased the LD to RW likelihood, whereas negative coefficients for foliage reduced the likelihood. Only the bedding plants groups were not significant, and size differences were not observed.

Generally, the measures of contract activity did not favor an increase in the likelihood of sales to landscapers. All significant variables for large growers reduced the LD to RW likelihood as did the variable contracts with other producers for small growers. Only contracts with garden centers increased the LD to RW likelihood. The results appeared to differ by size.

When the kinds of promotions were considered, higher trade shows promotion expenditures by large growers and trade shows attended by small growers reduced the LD to RW likelihood. Neither of these was significant for the other size, indicating size differences.
Although most of the other variables included in the model were not significant, there were exceptions that significantly reduced the LD to RW likelihood. These included increasing age of the firm for large growers and uniqueness as a pricing factor and proportion of negotiated sales for small growers.

Relationships between channels. In this section of the article, we look at the multinomial logit results across the three comparisons to rewholesalers. We hypothesized that growers prefer to sell to garden centers and landscapers because the competitive framework encourages these channels to differentiate themselves through product quality and service rather than to be price-based competitors. Mass merchandisers and rewholesalers would be second choices because these customers are more price-sensitive but offer significant sales opportunities. The results provide some support for these ideas.

Two groups of variables - the plants group and contract production group - appeared to reveal important channel relationships. For the plant group results, the vines variable did not distinguish because all three comparisons were significant and increased the channel to RW likelihood. The LD to RW likelihood increased when sales of trees/ shrubs increased but was not significant in the other sections of the model. For bedding plant group, more sales increased the MM to RW likelihood significantly with little impact on the other comparisons. Finally, for foliage, the LD to RW likelihood decreased with increase in sales, so the rewholesaler channel was favored in this comparison. Compared with rewholesalers, the channels do differ when increases in the plant groups are 
considered. These results seem consistent with casual observation. In the case of mass merchandisers, one observes prominent displays of bedding plants and other low-priced plant materials with high product turnover. Garden centers and landscapers may be an outlet for larger and specialized plant materials that are appropriate to their customers. There is some suggestion that the garden center and landscaper comparisons differ from the mass merchandiser. Signs and significance levels differ for the trees/shrubs, bedding plants, and foliage groups.

The contracts variables also provide some evidence that sales to garden centers and landscapers have some common reaction to changes in contract levels and forms. When total sales under contract increased, the GC to RW likelihood decreased most, and the LD to RW likelihood had similar signs but only the large firm coefficient was significant. When there were contracts with other producers, significant coefficients were negative across the comparisons to rewholesalers, but for the mass merchandiser section only, the small firm was significant. On the other hand, contracts with garden centers did not appear to distinguish between channels. Contracts with mass merchandisers increased the MM to RW likelihood, whereas coefficients for the garden center and landscaper sections were negative but not significant except for large firms in the landscapers section of the model. Again, some similarities appeared to exist between reactions of the garden centers and the landscapers.

Promotion-oriented variables also revealed some differences between these comparisons. When number of trade shows attended increased, the MM to RW likelihood declined, but the GC to RW likelihood and the LD to RW likelihood were not significant. Similar differences, particularly for large firms, were observed for expenditures on trade shows, but the coefficient signs were reversed.

Finally, other variables included in the model were usually nonsignificant. One exception was the channel diversity variable, and there is some suggestion of a difference between garden centers and landscapers and mass merchandisers. The MM to RW likelihood decreased for the mass merchandiser comparison but was not significant for the garden center to rewholesaler and the landscaper to rewholesaler comparisons. Most other variables were not consistent in their impacts, as illustrated in the regional variables, in which location in the west reduced the LD to RW likelihood compared with firms in the south. This outcome may be related to distance of western growers from eastern urban markets and other customer concentrations.

\section{Conclusions}

This study provides econometric evidence about how characteristics of growers affect the choice among four marketing channels. Hypotheses and results from this multinomial logit are exploratory. There has been little discussion in the literature about changing channel use despite increasing market share gains by mass merchandisers.

Evidence from the model provides some evidence of support for our main hypothesis that channel choice is influenced by size and by different business characteristics. There were differences between large and small growers, but generally the study shows more similarity of behavior between sizes than might have been expected. However, some variables do provide the beginning of a profile of the large and the small grower. Generally, regional differences were thought to be important, but we found little significance or size distinction there. Identification of plant groups that are important to different channels is documented in growers' use of channels. Similar statements may be made with respect to the contracting behavior and the promotion efforts groups of variables.

This study is expected to aid growers' understanding of their opportunities through analysis of market channels, because business characteristics may favor one channel or size over another. The study is exploratory, providing results that must be subjected to additional research for confirmation. In addition, this data set and modeling have limitations. Analysis is based on growers' reports of their marketing and production activities and is a view from the supply side. A balanced view would account for demand factors, including choices made by customers, managerial choices by end users, institutional factors, and the status of the overall economy, because these affect the propensity to use specific market channels. It was noted that the form of the MNL's dependent variable of choice does not match precisely with a variable in the data set, so assumptions and procedures were developed to assign observations to choices, if necessary. Finally, there were observations incomplete in critical aspects, and approximately half were not included in the analysis.

\section{Literature Cited}

Brooker, J., D. Eastwood, C. Hall, K. Morris, A. Hodges, and J. Haydu. 2005. Trade flows and marketing practices within the United States nursery industry: 2003. Tennessee Agricultural Experiment Station. Southern Cooperative Bulletin 404.

Dillman, D. 2000. Mail and Internet surveys: The total design method. 2nd Ed. Wiley, New York, NY.

ERS/USDA. 2007. Floriculture and nursery crops yearbook. 11 Oct. 2007. <http://www.ers.usda. gov/publications/flo/2007/09Sep/FLO2007.pdf >.

Hampton, W. 2001. Trade flows and marketing practices of Louisiana and Gulf states nurseries. MS thesis. Louisiana State University. 199.

Hinson, R. and S. Turner. 1994. Choice of nurseryappropriate marketing channels in the landscape plant industry. Journal of Environmental Horticulture. 12:76-79.

Pindyck, R. and D. Rubinfield. 1998. Econometric models and economic forecasts. 4th Ed. Irwin/ McGraw Hill, Boston, MA.

StataCorp LP. 2005. User's guide. Stata Press, College Station, TX. 